University of Wollongong

Research Online

Faculty of Social Sciences - Papers (Archive) Faculty of Arts, Social Sciences \& Humanities

2013

Relative importance of abstinence in clients' and clinicians' perspectives of recovery from drug and alcohol abuse

\author{
Lauren Maffina \\ University of Wollongong, lam371@uowmail.edu.au \\ Frank P. Deane \\ University of Wollongong, fdeane@uow.edu.au \\ Geoffrey C.B Lyons \\ University of Wollongong, glyons@uow.edu.au \\ Trevor P. Crowe \\ University of Wollongong, tcrowe@uow.edu.au \\ Peter J. Kelly \\ University of Wollongong, pkelly@uow.edu.au
}

Follow this and additional works at: https://ro.uow.edu.au/sspapers

Part of the Education Commons, and the Social and Behavioral Sciences Commons 


\title{
Relative importance of abstinence in clients' and clinicians' perspectives of recovery from drug and alcohol abuse
}

\begin{abstract}
This study collected data on drug and alcohol workers' $(n=55)$ and clients' $(n=139)$ perspectives on what constitutes a "recovery" from substance use disorder. Data were collected during 2010 from four residential faith-based treatment programs across the east coast of Australia. Self-report surveys specifically designed for this study were administered. Responses were compared using nonparametric test. Abstinence was seen as an important component of recovery but nonabstinent factors were also seen as having an important role. Staff placed more emphasis on clients taking responsibility for their problems and on the role of spiritual development. The importance of nonabstinence components was positively associated with a person's time in treatment and recovery. Implications, limitations, and future directions are noted.
\end{abstract}

\section{Keywords}

clinicians, clients, abstinence, importance, perspectives, relative, abuse, recovery, drug, alcohol

\section{Disciplines}

Education | Social and Behavioral Sciences

\section{Publication Details}

Maffina, L., Deane, F. P., Lyons, G. C. B., Crowe, T. P. \& Kelly, P. J. (2013). Relative importance of abstinence in clients' and clinicians' perspectives of recovery from drug and alcohol abuse. Substance Use and Misuse, 48 (9), 683-690. 
Running Head: PERSPECTIVES OF RECOVERY

Relative importance of abstinence in clients' and clinicians’ perspectives of recovery from drug and alcohol abuse

Lauren Maffina, Frank P. Deane, Geoffrey C. B. Lyons, Trevor P. Crowe \& Peter J. Kelly Illawarra Institute for Mental Health, University of Wollongong

Author for correspondence: Geoffrey Lyons, Illawarra Institute for Mental Health, School of Psychology, University of Wollongong, Wollongong, NSW, Australia, 2500. Telephone: +61 2 4221 4207, Email: glyons@uow.edu.au 


\section{ABSTRACT}

This study collected data on drug and alcohol workers’ $(n=55)$ and clients’ $(n=139)$ perspectives on what constitutes a 'recovery' from substance use disorder. Data was collected during 2010 from four residential faith-based treatment programs across the east coast of Australia. Self-report surveys specifically designed for this study were administered. Responses were compared using non-parametric test. Abstinence was seen as an important component of recovery but non-abstinent factors were also seen as having an important role. Staff placed more emphasis on clients taking responsibility for their problems and on the role of spiritual development. The importance of non-abstinence components was positively associated with a person's time in treatment and recovery. Implications, limitations and future directions are noted. This study was funded by The Australian Salvation Army Eastern Territories Division. 


\section{INTRODUCTION}

'Recovery' is a commonly used term in drug and alcohol research and may broadly be considered as a reduction in substance misuse accompanied by increased functionality. However, attempts to develop an operational definition of 'recovery' from substance use problems are a relatively recent occurrence (McLellan, 2010; Belleau et al., 2007). Previously, the dominant definition of 'recovery' in drug and alcohol research has been based on a disease model of substance misuse. This conceptualisation has emphasised abstinence from substance use as essential for recovery (Burman, 1997; Flynn, Joe, Broome, Simpson \& Brown, 2003; Grantfield \& Cloud, 2001; Scott, Foss \& Dennis, 2005). However, such definitions have limitations. Relapse after substance abuse treatment is common (Allsop, Saunders \& Phillips, 2000), but may be seen as learning experiences and part of the 'recovery' journey. Furthermore, the majority of people (85-95\%) admitted to addiction treatment are dependent on tobacco (White, 2008), potentially excluding a significant number of people from an abstinence-based definition of 'recovery'. A further issue is whether medication-assisted 'recovery', such as opiate replacement therapy, fits an abstinence-based definition of recovery (White, 2007). Thus, other factors besides substance use should be considered when defining 'recovery'.

More contemporary views of 'recovery' focus not just on symptom reduction, but rather on quality life despite the possible enduring presence of illness symptoms (Andresen, Oades \& Caputi, 2003). These conceptualisations incorporate broader, more inclusive definitions of the critical elements of 'recovery' (Belleau et al., 2007; Coyhis \& Simonelli, 2008; Kleinig; 2008; Kubicek, Morgan \& Morrison, 2002; Laudet, 2008, 2007; Laudet \& White, 2010; White, 2007). Laudet (2007) conducted a study of 289 people with a history of substance misuse. When given a four item forced choice response, the majority endorsed total abstinence as being important to the definition of 'recovery' (86.5\%). However, when asked 
to supply an open-ended definition of 'recovery', only $44.3 \%$ of the responses mentioned substance use. These results could indicate that although abstinence may be seen as an important element to 'recovery', it may not be the most important. Instead occupational, social and educational factors are likely considered important to recovery (White, 2007; Belleau et al., 2007; Laudet, 2008, Laudet, 2007; Coyhis \& Simonelli, 2008). Similarly, the reformation of social relationships (Kleinig, 2008; McLellan, McKay, Forman, Cacciola \& Kemp, 2005), community engagement (Belleau et al., 2007; Coyhis \& Simonelli, 2008; McLellan et al., 2005), finding meaning in life (Kleinig, 2008; White, 2007; Laudet \& White, 2010) and spiritual connections (Coyhis \& Simonelli, 2008) may play a role in recovery. Research also suggests a temporal relationship between a person's conceptualization of 'recovery' and the time spent actively managing substance use problems. People who have been on the 'recovery journey' longer place more emphasis on non-abstinent related goals, such as employment, education, family reunification, emotional and physical health, and spirituality (Laudet \& White, 2010). In contrast, those with less time actively addressing their substance use problems are more focused on the abstinence related goals (Margolis, Kilpatrick \& Mooney, 2000).

In short, 'recovery' is increasingly being recognised as being broader than just abstinence (McLellan, 2010; The Betty Ford Institute Consensus Panel, 2007) and is a concept that may shift as a person addresses their substance use problems (Laudet \& White, 2010; Margolis et al., 2000). Clinicians working in the drug and alcohol field may, through their supportive role, have more experience with the recovery journey than many clients presenting for treatment (Long, Midgley \& Hollin, 1997). Clinicians’ views of recovery may therefore be different from clients (Walton, Blow \& Booth, 2000; Long, Midgley \& Hollin, 1997). However, research has not compared staff and client definitions of 'recovery'. By clarifying the expectations of clients and staff regarding the elements of 'recovery' there is 
potential for both groups to work more collaboratively in establishing treatment goals, which in turn may increase treatment engagement. This study aimed to address this issue by comparing and contrasting client and staffs' definitions of 'recovery'. It was hypothesised that clients would rate non-abstinent related elements of recovery as less important to recovery than staff. It was also hypothesized that clients that had been in 'recovery' for longer would place more emphasis on non-abstinence elements than those who have been in 'recovery' for shorter amounts of time.

\section{METHODS}

\section{Participants}

Participants for the study consisted of staff $(n=55)$ and clients $(n=139)$ from four Salvation Army residential Recovery Services Centres located across the east coast of Australia. These faith-based programs provided a 10-month treatment approach that involved a combination of skills training, psycho-education, 12-step based interventions and individual case management and counselling. Demographics common to both staff and clients are presented in Table 1.

\section{----INSERT TABLE 1----}

The majority of treatment providers were employed as case workers (65.5\%) with 21.8\% having supervisory roles, $7.3 \%$ as AOD support workers and $5.4 \%$ as other treatment staff. The mean number of years they had worked in the drug or alcohol field was 5.05 (range from 0.5 to $19, \mathrm{SD}=3.89)$ and approximately half $(54.5 \%)$ had undergone drug and alcohol treatment themselves.

Clients' time in the service ranged from 1 to 52 weeks $(M=19.1, S D=10.09)$. Substances used varied across participants, with 90.6\% reporting use of alcohol, $64.7 \%$ marijuana, $49.6 \%$ amphetamines, $31.7 \%$ ecstasy, $25.2 \%$ cocaine, $18 \%$ heroin, and $21.6 \%$ other substances. Many of the participants had previously entered treatment programs, with 
52.5\% residential, 30.2\% 12-step programs, $12.9 \%$ using outpatient services, and $11.5 \%$ other forms of programs. Over half (65.5\%) had also attempted recovery without the use of a treatment program at some stage. Clients reported having difficulties with alcohol and substance use ranging from less than a year up to 50 years $(M=19$ years, $S D=10)$. A strong majority (94.2\%) of the sample stated that they felt they were in recovery, with a recovery time range from one week to 108 months $(\mathrm{M}=6.2$ months, $\mathrm{SD}=10)$.

\section{Measures}

The Attitudes Towards Recovery Survey (ATR). Two versions of this survey were developed, one for clients and one for staff. The client version ATR consisted of 25 items. Six items asked about basic demographics such as age, gender, ethnic background, education, and their current treatment admission. The other 19 questions asked about previous treatment attempts, past substance use behaviours, primary substance of abuse, time in treatment, and past mental health problems (including past psychiatric diagnoses). Three of these items were open-ended questions about recovery conceptualisations: "How would you define recovery from drug and alcohol use?”, "How would someone know if they were in recovery from drug and alcohol use?”, “Do you consider yourself to be in recovery?” If so, how long have you been in recover for?”. The Staff ATR consisted of 18 items. The first four items addressed demographics of age, gender, ethnicity and education. Seven questions asked about their current employment, such as position and duration in current position. Three items asked about past substance use problems and recovery attempts. Two qualitative items asked about recovery conceptualisations (as above) and invited a written response. In addition, both staff and client participants were asked: "What is your personal attitude to drug use in recovery?" and were instructed to choose from one of five responses. "1. Can use drugs and alcohol except the problem drug. 2. Can have controlled use of drugs and alcohol through recovery as long as it has no serious negative consequences for health and wellbeing. 3. Can have periods 
of drug and alcohol use as long as the majority of the time in recovery is drug and alcohol free. 4. Must abstain from all alcohol and drug use. 5. Other (please supply your own definition)”. This final question was based on the methodology of previous research (Laudet, 2007).

Elements of Recovery Questionnaire (ERQ). A modified version of the Recovery Beliefs Questionnaire (RBQ) (Crowe et al. unpublished data) was developed to clarify participants understanding of recovery. Twenty-two possible elements of recovery were listed (see Table 2) and participants were asked to rate how important they believe these are to recovery on a 7 -point Likert scale $(1=$ not at all important; $7=$ of critical importance). The first 15 items were adapted from the Recovery Beliefs Questionnaire. The next 4 items were taken from Flanagan (1978), one from Laudet $(2007,2008)$ and the final two from themes discussed in Kleinig (2008).

Procedure

Staff were informed of the study by their manager or team leader. Those wishing to participate were provided with a survey package that included the ATR, ERQ, a participant information sheet and a consent form. Staff participants then completed the survey and returned it to a secure drop box located at each residential rehabilitation centre. Client participants were first informed about the study by staff and if they remained interested in participating attended a recruitment meeting at their Recovery Service Centre. Researchers provided clients with the survey package and answered any questions about the study. Participants returned their surveys, whether completed or not, to a sealed drop box located in the meeting room. All procedures were reviewed and approved by the University of Wollongong Human Research Ethics Committee.

\section{RESULTS}

\section{Clients and staff's views on substance use and its compatibility with recovery}


The majority of clients (94.9\%) agreed with the statement that full abstinence was required to be considered in recovery. Only 5.1\% agreed with any of the other statements which allowed some use of drugs or alcohol in recovery. The pattern for staff responses was similar, with the majority (72.7\%) agreeing that abstinence from all substances was required to be in recovery. The next highest was the 'other' definition (21.8\%), where many participants made allowances for relapses and made mention of the importance of other elements of recovery. In the third highest category only two (3.6\%) respondents felt that some periods of drug and alcohol use was compatible with recovery as long as the majority of time in recovery was drug free and one respondent felt that controlled use of drugs and alcohol is compatible with recovery as long as it has no serious consequences for health and wellbeing.

A Chi-square test for independence (with Yates Continuity Correction) was conducted to determine if differences existed between staff and client ratings for the total abstinence versus non-abstinence options. All responses that were other than the full abstinence response were grouped together into an 'other' category. The chi-square test was significant with a greater proportion of clients endorsing the abstinence response (94.9\%) than staff $(72.7 \%), \chi^{2}$ $(1, \mathrm{n}=191)=18.81, p<.001$, phi $=-.31$.

\section{Recovery elements most important for clients}

To determine which recovery elements were considered most important by clients and staff, means of scores on the ERQ were calculated. Once the ranks were determined, participants with missing data from the top 5 staff and the top 5 client rated elements were excluded from the analysis to determine mean rated importance. The results are included in Table 2. 
Paired Wilcoxon signed ranks tests were conducted to determine whether there were differences between the rated importance of the abstinence element and other non-abstinence elements. For clients, there were no significant differences found between the two elements ranked immediately after abstinence ("loving relationships" and "a second chance”) and the abstinence element. For staff, there were no significant differences found for rated importance between the top 5 elements ("increased responsibility for recovery", "spiritual development”, “overcoming obsessions”, “greater self-acceptance”) and the abstinence element.

\section{Time in treatment, time in recovery and importance of recovery elements}

Spearman's correlations were run to determine if clients' time in treatment was associated with their importance ratings. Time in treatment was positively correlated with item 2 (“Abstinence from drug and alcohol use”), $r_{s}=.19, p<.05$, and item 7 ("Having more people you care about”), $r_{s}=.21, p<.05$ of the Elements of Recovery Questionnaire. The mean time in treatment (19.1 weeks) was used to separate clients into two categories: those who had been in treatment 19.1 weeks or less $(n=68)$ and those who had been in treatment for more than 19.1 weeks $(n=65)$. Mann-Whitney U tests found no significant differences between those who had been in treatment for longer and those in treatment for shorter periods of time $(p>.05)$.

Spearman's correlations were used to determine if clients’ perceived time in recovery was correlated with their importance ratings. Item 9, "Spiritual development", was significantly correlated with perceived time in recovery, $r_{s}=.26, p<.01$. No other correlations were significant. Participants' mean perceived time in recovery was (6.2 months) used to categories participants into 'recent' and 'long-term' recovery. Participants who rated themselves as being in recovery for 6.2 months or less, were placed in the 'recent' recovery group $(\mathrm{n}=78)$. Those with more than 6.2 months were placed in the 'long-term' group $(\mathrm{n}=$ 
51). A Mann-Whitney U test found that participants in the 'recent' recovery group reported “spiritual development” as more important than those in the 'long-term' group $U=1445, z=$ $-2.43, p<.01, r=-.21$.

\section{Rated importance of elements of recovery across staff and clients}

To examine whether reported importance of the ERQ recovery elements differed between staff and clients, non-parametric tests were conducted using the top 5 recovery elements for staff and clients. This resulted in eight unique elements which appear in italics in Table 2. Eight Mann-Whitney U tests were conducted using a Bonferroni adjusted alpha $(.05 / 8=.006)$. Item 9 , "Spiritual development" was found to differ significantly between staff and clients, with staff $($ Rank $=2)$ rating this element as significantly more important than clients $($ Rank $=16) U=2181.50, z=-3.92, p<.001 r=-0.29 . \quad$ Item 1 , "Increased responsibility" was also found to differ significantly between staff and clients, with staff $($ Rank $=1)$ rating this element as significantly more important than clients $($ Rank $=6) U=$ 2376.50, $z=-3.34, p=.001, r=0.25$. Item 21, “Loving relationships” was rated significantly higher by clients $($ Rank $=3)$ than staff $($ Rank $=14) U=2340, z=-3.47, p=.001, r=-.26$. Item 20, “A second chance” was also rated significantly higher by clients (Rank $=4$ ) than staff $($ Rank $=13) U=2455, z=-3.03, p=.002, r=-0.23$. None of the other four elements was found to differ significantly between staff and client ratings of importance.

\section{Differences in importance rating between staff with and without a history of treatment}

Mann-Whitney U tests were conducted to determine if having a history of substance abuse treatment influenced staffs' conceptualizations of recovery. The elements of the ERQ were used as dependent variables with a Bonferroni corrected alpha of .002 $(.05 / 22=.002)$. No significant differences in importance ratings were seen between those with and without a history of substance abuse treatment $(p>.05)$. Item 2, "Abstinence from drug and alcohol 
use”, item 9 "Spiritual development” and item 11 "Use of drugs and alcohol in a controlled way”, were approaching significance $(p<.05)$.

\section{DISCUSSION}

Although abstinence was rated highly by both staff and clients in regards to drug use in 'recovery', a significantly higher proportion of clients than staff agreed that to remain in 'recovery', you must be abstinent from all alcohol and drug use. Staff who did not choose this definition generally chose the 'other' category, seeing abstinence as important but with some quantifier such as relapses being consistent with the 'recovery' process. There were other elements of recovery that were rated as being just as important as abstinence. Although abstinence is still an important element, this may indicate that it should not be the only indicator considered in judging the success of programs or clients completing programs.

Non-abstinence elements also showed some variation across staff and clients. Spiritual development and taking on increased responsibility for 'recovery' were rated significantly higher by staff than clients. The differences in spiritual development finding likely reflects that services have "faith-based" elements with The Salvation Army as the provider. However, given the further finding that clients rate spiritual development as more important as they progress further in their recovery journey, it may also reflect the recovery journey of staff, because many of the staff were also in recovery from drug and alcohol abuse. Further studies should clarify whether spiritual development is of similar importance in non faith-based programs.

There are a number of ways of interpreting the finding that staff view taking on increased responsibility for recovery as significantly more important than clients did. The taking of responsibility requires both ownership and action, which are affected by the meaning associated with them (Deci \& Ryan, 2000). If recovery goals and actions are pursued because they reflect being the person the client wants to be (i.e., there is high goal 
ownership that is integrated with self, Elliot \& Sheldon, 1997) or because it is associated with intrinsic motivation, they will likely exhibit behaviours that reflect taking personal responsibility for their recovery in a sustained way (Deci \& Ryan, 2000). Conversely, if the recovery goals and actions are pursued because they are only about avoiding negative consequences (e.g., legal problems, illness, family breakdown), the motivation is extrinsic and therefore will tend to be time limited, and perhaps less important than other goals (Deci \& Ryan, 2000). There also may be other personal barriers to taking responsibility substance abuse contexts, such as unresolved interpersonal resentment, shame or need for forgiveness (Lyons, Deane \& Kelly, 2010), or not being ready to accept life events associated with substance abuse.

An important question here is related to how staff and clients interpret, "taking responsibility for recovery”? If recovery is only defined by disorder management, then it may be that staff see lack of treatment program engagement or relapse as a sign that the client has failed to adequately take responsibility to manage the symptoms of the disorder. Conversely, clients holding this view of recovery may consider it, at least in some part, the treatment service's responsibility to "fix" the disorder. Interestingly, the endorsement of taking on responsibility did not change significantly for clients the longer they were in recovery. This may simply be offering further support for the finding that clients consider other features of recovery as more important (e.g., overcoming obsessive thinking), but it might also be suggesting that not enough emphasis is being placed within the current treatment program on ensuring that the recovery goals are "owned" by the client.

Loving relationships and a second chance at life were rated as higher in importance by clients than staff. This suggests that these may be areas that should be addressed by treatment programs to foster greater concordance between staff and clients definitions, and to rebuild support networks. The importance rating of 'a second chance at life', which was also a theme 
of 'recovery' identified by participants as important in Laudet (2007) is particularly interesting given that the treatment program has faith-based elements. That is, the importance of a second chance at life may link in with ideas of redemption and their relation to faithbased 'recovery' programs (White, 2005). Getting a second chance may also be closely related to the concept of forgiveness (for past wrongs) and forgiveness is a theme in both 12 step models and Christian faith (Lyons, Deane \& Kelly, 2010). Getting a second chance is also related to optimism and hope, particularly as those in long term recovery also have higher rated optimism than those in short term recovery (White, Ampler \& Fischer, 2001). Although The Salvation Army programs have faith-based elements, gaining a second chance has been raised by participants in a range of different programs, including those that had not attended a treatment program (Laudet, 2007). It is likely that ideas of forgiveness and gaining a second chance are also important to secular treatment programs, particularly since it is common for secular programs to also utilise 12-steps approaches (Magura, 2007). Research into 12 step programs has also demonstrated that some individuals, after working through 12 step programs, feel that a second stage of recovery is warranted, with further self-growth a priority (Nixon \& Solowoniuk, 2008).

The study has several implications for treatment programs. Although, abstinence is considered important to recovery several other elements of recovery such as relationships with others, spirituality, personal responsibility were also important to staff and clients. The importance of relationships to clients highlights the need for firstly, identifying the relationship needs of clients and then targeting appropriate interventions. A wide range of interpersonal relationship factors have been identified as important in the treatment of individuals with substance abuse problems. For example, family conflict (Asche \& Harrison, 2002), problems with attachment, interpersonal functioning and intimacy are common (Thorberg \& Lyvers, 2010). The importance of "loving relationships” in the current study 
suggests it is important to clarify the type of relationship needs for clients and where possible provide appropriate treatment. Prior research suggests that substance abuse programs in the USA have been responsive to family relationship counselling needs (Asche \& Harrison, 2002).

Where there are discrepancies between staff and client views of important components of recovery should also be addressed by treatment programs. In the present study this relates particularly to the relatively strong endorsement of "spiritual development" by staff. Again, there is a need for further clarification of the meaning of this item since in the current context it is likely staff viewed this from the faith-based Christian foundations of the Salvation Army programs. Seeking a good match between client preferences and needs and different service types may be important at service seeking stage. Further, clarifying the broad meaning of spirituality to include 12-step components such as acceptance of a higher power, forgiveness and development of meaning in life might help clients view spirituality as being more relevant to their recovery.

At an even broader level our results indicate the need to educate clients about the multiple areas of their lives that can change to support their recovery.

\section{Strengths and limitations of the study}

This study is one of the first to directly compare staff and client's definitions of 'recovery'. It is also one of the first to use a sample from areas across Australia to show generalizability of earlier results in countries such as the United States. However, there are some limitations including the client sample which was sourced from residential treatment programs, and as such many reported only being in 'recovery' for a short period of time (mean time of recovery rated as 6.2 months). In contrast prior studies have used samples that reported being abstinent for at least one year (Laudet \& White, 2010; Laudet, 2007). If the sample were in 'recovery' for a longer duration of time, it is possible that other non- 
abstinence elements, such as educational opportunities, would be rated as more important for those longer in 'recovery’(e.g., as found by Laudet \& White, 2010). Also, by using clients from one faith-based program, the results may not be as applicable to clients involved in other treatment programs. Further research would need to be conducted using other treatment approaches, or using other methodologies such as qualitative interviews to confirm these findings. Additionally, the voluntary nature of the recruitment process potentially biased the sample from which the data was drawn. Perceptions of recovery may be different for treatment providers and clients who decline to share their views. A final consideration is that many of the participants were likely to be experiencing co-morbid mental health issues (Mortlock, Deane \& Crowe, 2011). It is possible given the development in 'recovery' definitions in mental health other than drug and alcohol abuse that this could affect the importance of different elements of recovery.

\section{Conclusion}

The study found that most clients and staff in faith-based programs agree that abstinence is required for recovery, and this conceptualisation is positively associated with time in treatment. However, this view may be significantly less among workers, who tend to place more emphasis on non-abstinent components, such as spiritual development and accepting responsibility. These goals may generally be seen to be reflective of intrinsic goals or an internal locus of control. Clients, on the other hand, emphasized non-abstinent goals with a more external locus of control; such as being given a second chance and being part of loving relationships. Future research should explore shifts in recovery perceptions from external to internal locus of control and extrinsic to intrinsic goals. There was also some evidence that time in treatment and time in perceived recovery is associated with more internally-orientated goals such as spiritual development and being able to care for others. The findings suggest that though abstinence is important to 'recovery', it alone may not be 
sufficient to be considered 'in recovery'. Treatment programs need to address a broad range of areas regarding life functioning for clients, and abstinence should not be the only measure used to determine their success in addresses substance use problems.

\section{Declaration of interests}

This study was funded by a research consultancy to the second, fourth and fifth authors from The Australian Salvation Army Eastern Territories Division. The authors report no other conflicts of interest. 


\section{REFERENCES}

Allsop, S., Saunders, B. \& Phillips, M. (2000). The process of relapse in severely dependent male problem drinkers. Addiction, 95, 95-106.

Andresen, R., Oades, L., \& Caputi, P. (2003). The experience of recovery from schizophrenia: Towards an empirically validated stage model. Australian and New Zealand Journal of Psychiatry, 37, 586-594.

Asche, S. E. \& Harrison, P. A. (2002). The relationship between problem severity and ancillary treatment services; Is substance abuse treatment responsive to client need? Journal of Behavioral Health Services \& Research, 29, 345-356.

Belleau, C., DuPont, R. L., Erikson, C. K., Flaherty, M. T., Galanter, M. Gold, M., Kaskutas, L. A., Laudet, A., McDaid, C., McLellan, A. T., Morgenstern, J., Rubin, E., Schwarzlose, J., \& White, W. (2007). What is recovery? A working definition from the Betty Ford Institute. Journal of Substance Abuse Treatment, 33, 221-228.

Burman, S. (1997). The challenge of sobriety: Natural recovery without treatment and selfhelp programs. Journal of Substance Abuse, 9, 41-46.

Coyhis, D., \& Simonelli, R. (2008). The Native American healing experience. Substance Use \& Misuse, 43, 1927-1949.

Davidson, L., \& Roe, D. (2007). Recovery from versus recovery in serious mental illness: One strategy for lessening confusion plaguing recovery. Journal of Mental Health, $16,459-470$.

Elliot, A. J., \& Sheldon, K. M. (1997). Avoidance achievement motivation: A personal goals analysis. Journal of Personality and Social Psychology, 73, 171-185.

Flanagan, J. C. (1978). A research approach to improving our quality of life. American Psychologist, 33, 138-147. 
Flynn, P., Joe, G., Broome, K., Simpson, D., \& Brown, B. (2003). Looking back on cocaine dependence: Reasons for recovery. American Journal on Addictions, 12, 398-411.

Goldstein, J. M., Cohen, P., Lewis, S. A., \& Struening, E. L. (1988). Community treatment environments: Patient vs. staff evaluations. Journal of Nervous and Mental Disease, 176, 227-233.

Grantfield, R., \& Cloud, W. (2001). Social context and "natural recovery": The role of social capital in the resolution of drug-associated problems. Substance Use \& Misuse, 36, 1543-1570.

Hawkins, E. J., Baer, J. S., \& Kivlahan, D. R. (2008). Concurrent monitoring of psychological distress and satisfaction measures as predictors of addiction treatment retention. Journal of Substance Abuse Treatment, 35, 207-216.

Keyes, C. L. (2007). Promoting and protecting mental health as flourishing: A complementary strategy for improving national mental health. American Psychologist, 62, 95-108.

Kleinig, J. (2008). Recovery as an ethical ideal. Substance Abuse \& Misuse, 43, 1685-1703.

Kubicek, K. R., Morgan, O. J., \& Morrison, N. C. (2002). Pathways to long-term recovery from alcohol dependence: Comparison of spontaneous remitters and AA members. Alcoholism Treatment Quarterly, 20, 71-81.

Laudet, A. (2008). The road to recovery: Where are we going and how do we get there? Empirically driven conclusions and future directions for service development and research. Substance Use \& Misuse, 43, 2001-2020.

Laudet, A. B. (2007). What does recovery mean to you? Lessons from the recovery experience for research and practice. Journal of Substance Abuse Treatment, 33, 243256. 
Laudet, A. B., \& Stanick, V. (2010). Predictors of motivation for abstinence at the end of outpatient substance abuse treatment. Journal of Substance Abuse Treatment, 38, 317327.

Laudet, A. B., \& White, W. L. (2010). What are your priorities right now? Identifying service needs across recovery stages to inform service development. Journal of Substance Abuse Treatment, 38, 51-59.

Laudet, A. B., Becker, J. B., \& White, W. L. (2009). Don't wanna go through that madness no more: Quality of life satisfaction as predictor of sustained remission from illicit drug misuse. Substance Use \& Misuse, 44, 227-252.

Long, C. G., Midgley, M. \& Hollin, C. R. (1997). Staff Do Know Best: Peer \& Therapist Prediction of Outcome Following Treatment for Problem Drinking. Addiction, Research \& Theory, 5, 235-249.

Lyons, G. C. B., Deane, F. P., Kelly, P. J. (2010). Forgiveness and purpose in life as spiritual mechanisms of recovery from substance use disorders. Addiction Research \& Theory, $18,528-543$.

Magura, S. (2007). The relationship between substance abuse treatment and 12 step fellowships: Current knowledge and research questions. Substance Use \& Misuse, 42, 343-360.

Margolis, R., Kilpatrick, A., \& Mooney, B. (2000). A retrospective look at long-term adolescent recovery: Clinicians talk to researchers. Journal of Psychoactive Drugs, 32, 117-125.

McLellan, T. (2010). What is recovery? Revisiting the Betty Ford Institute Consensus Panel Definition: The Betty Ford Consensus Panel and Consultants. Journal of Substance Abuse Treatment, 38, 200-201. 
McLellan, A. T., McKay, J. R., Forman, R., Cacciola J., \& Kemp, J. (2005). Reconsidering the evaluation of addiction treatment: From retrospective follow-up to concurrent recovery monitoring. Addiction, 100, 447-458.

Mortlock K. S, Deane F. P. \& Crowe T.P. (2011). Screening for mental disorder comorbidity in Australian alcohol and other drug residential treatment settings. Journal of Substance Abuse Treatment,40, 397-404.

Nixon, G. \& Solowoniuk, J. (2008). Moving beyond the 12-steps to a second stage recovery: A phenomenological inquiry. Journal of Groups in Addiction and Recovery, 3, 23-46.

Onken, S. J., Craig, C. M., Ridgeway, P., Ralph, R. O., \& Cook, J. A. (2007). An analysis of the definitions and elements of recovery: A review of the literature. Psychiatric Rehabilitation Journal, 31, 9-22.

Ramon, S., Healy, B., \& Renouf, N (2007). Recovery from mental illness as an emergent concept and practice in Australia and the UK. International Journal of Social Psychiatry, 53, 108-122.

Rodgers, M. L., Norell, D. M., Roll, J. M., \& Dyck, D. G. (2007). An overview of mental health recovery. Primary Psychiatry, 14, 76-85.

Ryan, R. M., \& Deci, E. L. (2000). Intrinsic and extrinsic motivations: Classic definitions and new directions. Contemporary Educational Psychology, 25, 54-67.

Scott, C. K., Foss, M. A., \& Dennis, M. L. (2005). Pathways in the relapse-treatmentrecovery cycle over 3 years. Journal of Substance Abuse Treatment, 28(Supp 1), S63S72.

Seligman, L. D., Wuyek, L. A., Geers, A. L., Hovey, J. D., \& Motley, R. L. (2009). The effects of inaccurate expectations on experiences with psychotherapy. Cognitive Therapy and Research, 33, 139-149. 
The Betty Ford Institute Consensus Panel (2007). What is recovery? A working definition from the Betty Ford Institute. Journal of Substance Abuse Treatment, 33, 221-228.

Thorbert, F. A., \& Lyvers, M. (2010). Attachment in relation to affect regulartaion and interpersonal functioning among substance use disorder in patients. Addiction Research \& Theory, 18, 464478.

Walton, M. A., Blow, F. C. \& Booth, B. M. (2000). A comparison of substance abuse patients' and counselors' perceptions of relapse risk: Relationship to actual relapse. Journal of Substance Abuse Treatment, 19, 161-169.

White, W. L. (2008). Recovery: Old wine, flavour of the month or new organizing paradigm? Substance Use \& Misuse, 43, 1987-2000.

White, W. (2007). Addiction recovery: Its definition and conceptual boundaries. Journal of Substance Abuse Treatment, 33, 229-241.

White, W. L. (2005). Recovery. Alcoholism Treatment Quarterly, 23, 3-15.

White, J. M., Wampler, R. S., and Fischer, J. L. (2001). Indicators of spiritual development in recovery from alcohol and other drug problems. Alcoholism Treatment Quarterly, 19, 19-35. 


\section{GLOSSARY}

Faith-based programs: The treatment programs incorporate religious or spiritual related material into their treatment program. The degree to which this occurs varies among programs and organizations. Some will use minimal spiritual components; others may rely entirely on religious material and support mechanism.

12-steps: The 12-step of Alcoholics Anonymous is one of the world's most common models for the treatment of substance related problems. It is based on the disease model of addiction and proposes that surrendering to a "Higher Power" leads to a transformation of character and recovery from substance misuse. The person is required to progress through a hierarchy of 12 stages to achieve recovery.

Opiate replacement therapy: A therapy for opioid dependence that involves replacing a person's illegal opiate, often heroin, with a controlled dosage of a longer acting and less potent opiate. 
Table 1.

Participant demographics and substance use histories

\begin{tabular}{|c|c|c|}
\hline & Staff & Clients \\
\hline Gender (\%): & 65.5 & 82 \\
\hline Female & 34.5 & 18 \\
\hline Age in years $(M)$ : & 46 & 38 \\
\hline$(S D):$ & 10.03 & 10.40 \\
\hline Treated for a substance use disorder (\%): & 54.5 & 100 \\
\hline Anglo-Saxon Australian & 86.5 & 81.1 \\
\hline Indigenous / Torres Strait Island Australian & 5.8 & 5.3 \\
\hline Other & 7.7 & 13.6 \\
\hline Higher School Certificate or less ${ }^{\mathrm{a}}$ & 5.7 & 60.3 \\
\hline Non-university tertiary (e.g. trade certificate) & 62.3 & 31.6 \\
\hline Undergraduate university degree & 17.0 & 2.9 \\
\hline Postgraduate university degree & 15.1 & 5.1 \\
\hline
\end{tabular}

${ }^{\mathrm{a}}$ An Australian Higher School Certificate is the equivalent of 13 years of education Staff, $n=55$; Clients, $n=139$ 
Table 2

Elements of recovery rated by clients and staff in order of importance.

\begin{tabular}{|c|c|c|c|c|c|c|}
\hline \multirow[t]{2}{*}{ Item number and element } & \multicolumn{3}{|c|}{ Clients (n = 129) } & \multicolumn{3}{|c|}{ Staff $(n=52)$} \\
\hline & Rank & Mean & $\mathrm{SD}$ & Rank & Mean & SD \\
\hline 22. Overcoming obsessions with drugs and & 1 & 6.47 & 1.02 & 4 & 6.42 & .96 \\
\hline \multicolumn{7}{|l|}{ alcohol } \\
\hline 02. Abstinence from drug and alcohol use & 2 & 6.35 & 1.09 & 3 & 6.54 & 0.78 \\
\hline 21. Having loving relationships with family & 3 & 6.34 & 0.98 & 14 & 5.71 & 1.24 \\
\hline \multicolumn{7}{|l|}{ and friends* } \\
\hline 20. Gaining a second chance at life* & 4 & 6.25 & 1.02 & 13 & 5.72 & 1.15 \\
\hline 16. Having good physical and emotional & 5 & 6.02 & 1.03 & 10 & 5.83 & 1.12 \\
\hline \multicolumn{7}{|l|}{ wellbeing } \\
\hline 01. Taking on increased responsibility for your & 6 & 5.96 & 1.25 & 1 & 6.62 & .60 \\
\hline \multicolumn{7}{|l|}{ own recovery* } \\
\hline 08. Pursuing goals that are in line with your & 7 & 5.95 & 1.11 & 9 & 6.00 & .86 \\
\hline \multicolumn{7}{|l|}{ personal values } \\
\hline 05. Having greater self acceptance & 8 & 5.95 & 1.25 & 5 & 6.29 & .78 \\
\hline 13. Having renewed purpose in life & 9 & 5.92 & 1.16 & 6 & 6.17 & .88 \\
\hline 17. Having a greater understanding of yourself & 10 & 5.90 & 1.23 & 7 & 6.13 & .97 \\
\hline
\end{tabular}


Perspectives of recovery 25
04. Feeling closer to others in your life
11
5.89
$1.19 \quad 16$
5.63
1.07
18. Working in a role that is interesting,
$12 \quad 5.86$
$1.14 \quad 15$
5.63
1.03
rewarding and worthwhile

14. Feeling you are able to make a contribution

13

5.82

1.08

12

5.75

1.03

to society

06. Being able to accept support from others

14

5.78

1.23

8

6.120 .96

10. Feeling cared for and accepted

15

5.64

1.33

11

5.77

1.08

09. Engaging in spiritual development*

16

5.56

1.64

2

6.56

0.70

12. Redefining who you are as a person

17

5.53

1.32

17

5.58

1.16

19. Participating in hobbies and recreational

18

5.52

1.32

18

5.54

1.00 activities

15. Finding a valued role or social niche

07. Having more people you care about

03. Overcoming stigma

11. Use of drugs and alcohol in a controlled way $^{\mathrm{a}}$ $\begin{array}{llllll}19 & 5.45 & 1.34 & 20 & 5.46 & 1.18\end{array}$

$\begin{array}{llllll}20 & 5.34 & 1.49 & 21 & 5.12 & 1.17\end{array}$

$\begin{array}{llllll}21 & 4.94 & 1.79 & 19 & 5.52 & 1.46\end{array}$

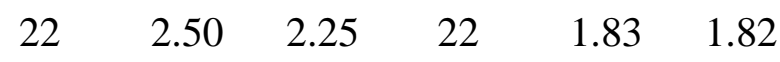

Note. Elements in italics are five highest rated for staff and five highest rated for clients in terms of importance to recovery. Ratings were on a 7-point Likert-type scale from $1=$ Not at all important 2 = Slightly important $3=$ Some importance $4=$ Important $5=$ Very important $6=$ Extremely important 7= Of critical importance. 
Perspectives of recovery 26

* Significantly different importance ratings between groups using Bonferroni adjusted $p<.006$.

${ }^{\mathrm{a}}$ This item had the most missing data $(\mathrm{N}=164)$ but was clearly rated the lowest by both staff and clients. 